\title{
Supporting Information \\ Scaffold-Like Titanium Nitride Nanotube with a Highly \\ Conductive Porous Architecture as a Nanoparticle Catalyst Support for Oxygen Reduction
}

\author{
Heejong Shin ${ }^{\mathrm{a}, \mathrm{b} \dagger}$, Hyoung-il Kim ${ }^{\mathrm{c} \dagger}$, Dong Young Chung ${ }^{\mathrm{a}, \mathrm{b}}$, Ji Mun Yoo ${ }^{\mathrm{a}, \mathrm{b}}$, \\ Seunghyun Weon ${ }^{\mathrm{c}}$, Wonyong Choi ${ }^{\mathrm{c} *}$ and Yung-Eun Sung ${ }^{\mathrm{a}, \mathrm{b} *}$
}

${ }^{a}$ Center for Nanoparticle Research, Institute for Basic Science (IBS), Seoul 151-742, Korea

${ }^{b}$ School of Chemical and Biological Engineering, Seoul National University, Seoul 151-742, Korea

${ }^{c}$ School of Environmental Science and Engineering, Pohang University of Science and Technology (POSTECH), Pohang 790-784, Republic of Korea

$\dagger$ These authors contributed equally to this work.

* Corresponding authors. E-mail: wchoi@postech.edu, ysung@snu.ac.kr. 


\section{Supporting Text}

Total electron-transfer number (n) determined by RRDE approach

The total electron-transfer number (n) in the catalyzed ORR were calculated as

$\mathrm{n}=\frac{4 I_{d}}{I_{d}+I_{r} / N}$

where $\mathrm{N}$ is the RRDE collection efficiency, which was determined to be 0.37 herein.

\section{Supporting figures and tables}

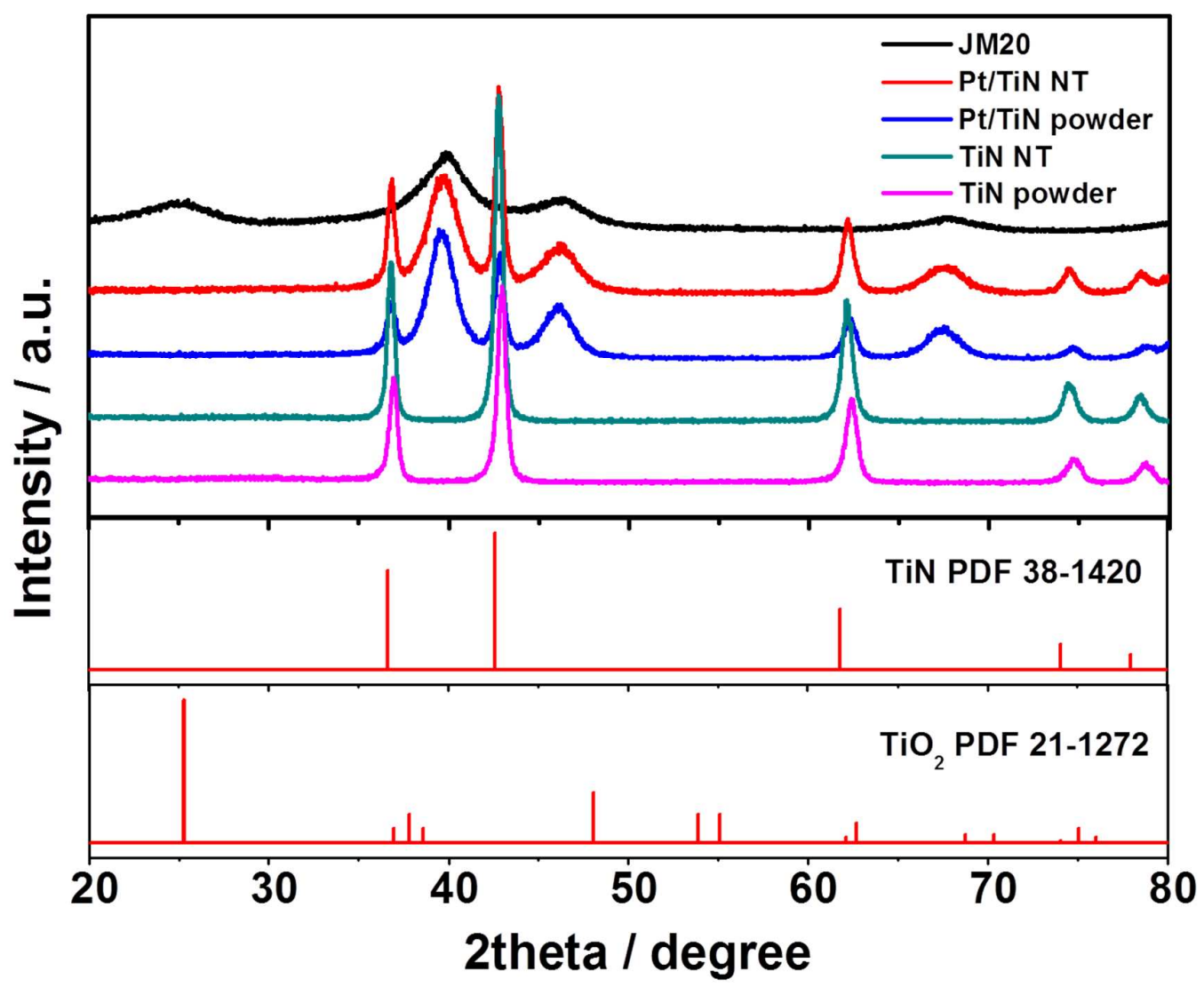

Figure S1. XRD patterns of TiN NT, TiN NP, Pt/TiN NT, Pt/TiN NP and Pt/C (Johnson Matthey 20wt\%). 


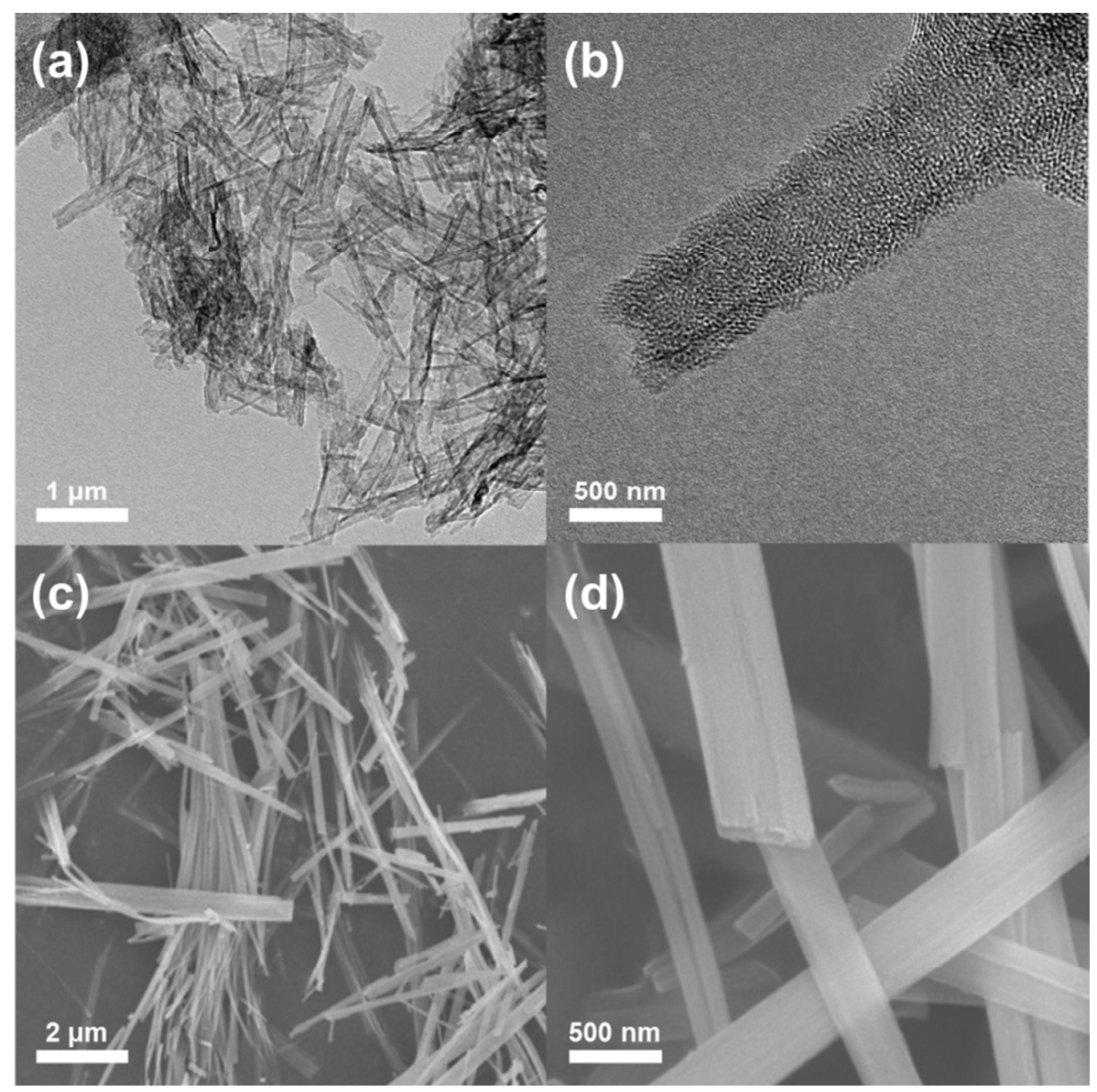

Figure S2. (a), (b) HR-TEM images of $\mathrm{TiO}_{2}$ nanofiber synthesized at $120{ }^{\circ} \mathrm{C}$ for $24 \mathrm{~h}$ and (c), (d) FE-SEM images of $\mathrm{TiO}_{2}$ nanofiber synthesized at $200^{\circ} \mathrm{C}$ for $48 \mathrm{~h}$. 
(a)

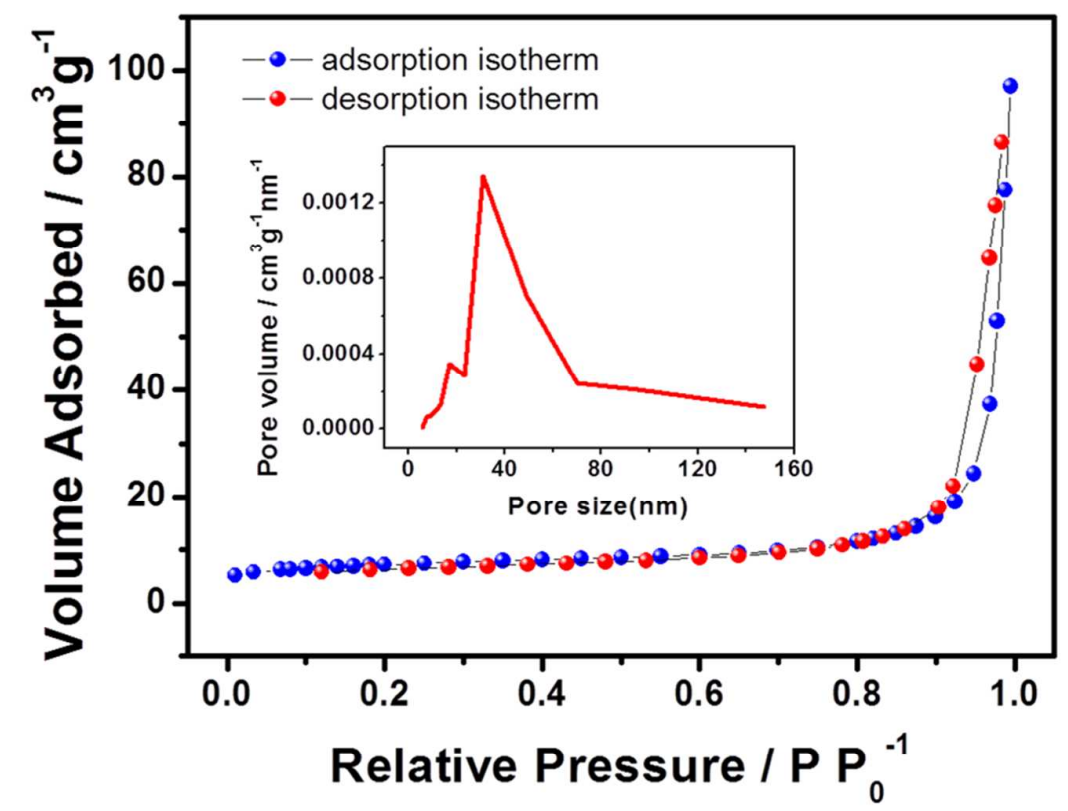

(b)

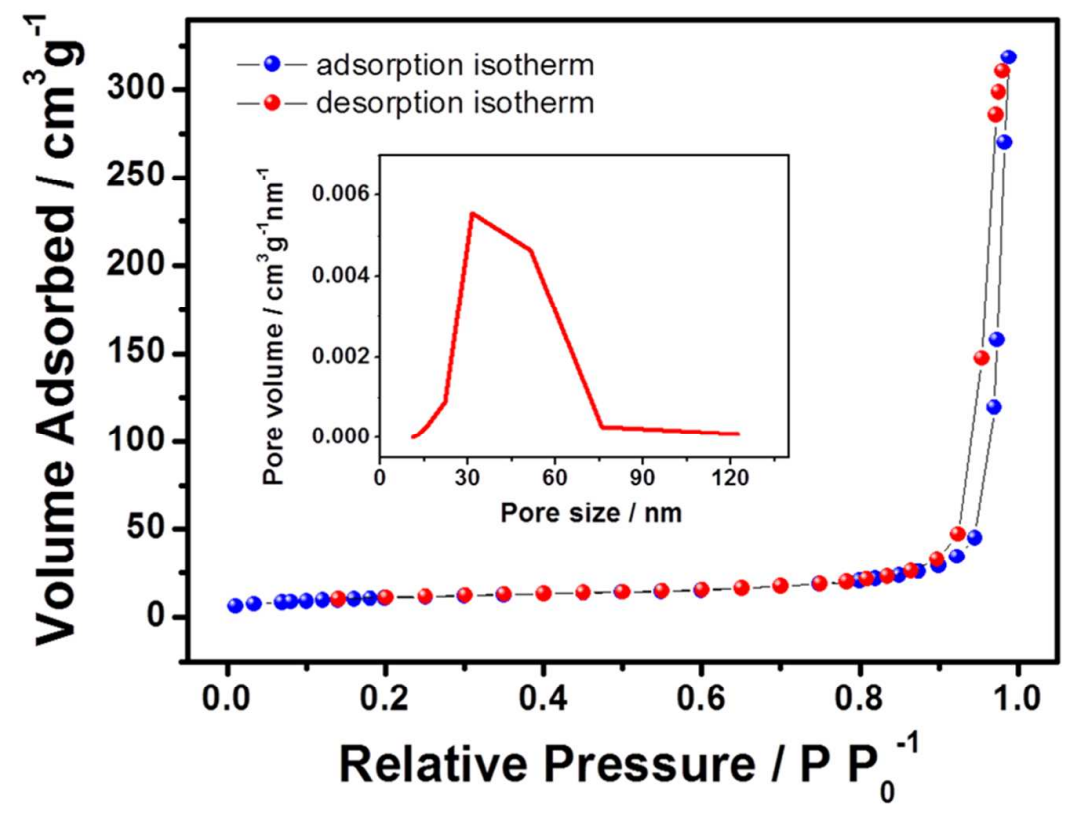

Figure S3. Nitrogen adsorption-desorption isotherms of (a) TiN NT and (b) TiN NP, and inserts are the corresponding Barrett-Joyner-Halenda (BJH) pore-size distributions. 

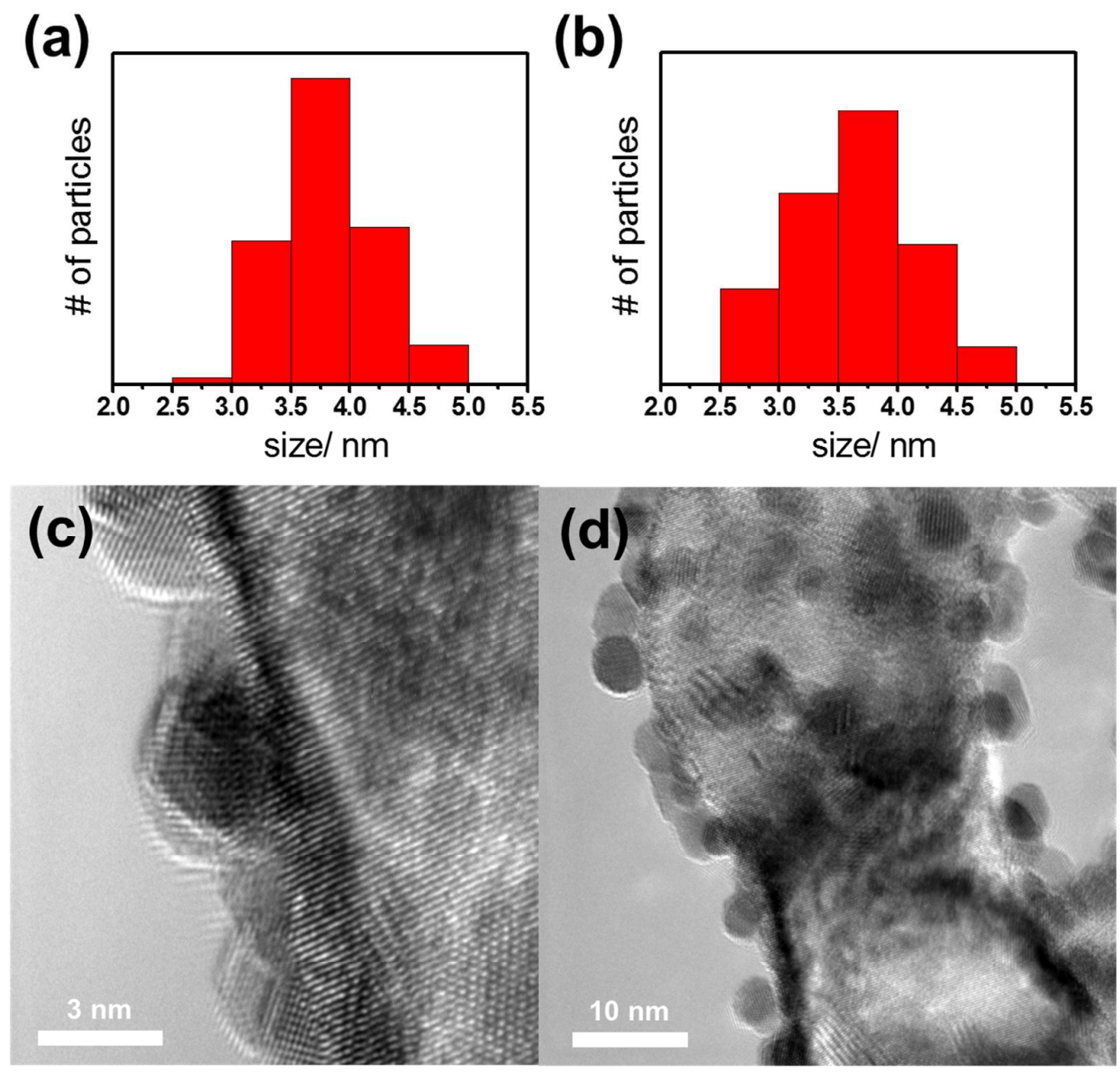

Figure S4. The size distribution histogram of Pt nanoparticles in (a) Pt/TiN NT and (b) Pt/TiN NP. (c) and (d) TEM images of Pt/TiN NTs with hemispherical Pt particles on TiN supports.

Table S1. The concentration of elements in samples $(\mathrm{ppb}=\mu \mathrm{g} / \mathrm{kg})$ by ICP-MS. The mass of titanium nitride was calculated from the measured Ti mass at the rate of the molecular weight of them.

\begin{tabular}{|c|c|c|c|c|}
\hline Sample & $\begin{array}{c}\text { Pt } \\
(\mu \mathrm{g} / \mathrm{kg})\end{array}$ & $\begin{array}{c}\text { Ti } \\
(\mu \mathrm{g} / \mathrm{kg})\end{array}$ & $\begin{array}{c}\text { Calculated } \\
\text { TiN }(\mu \mathrm{g} / \mathrm{kg})\end{array}$ & $\begin{array}{c}\text { Pt } \\
(\mathrm{wt} \%)\end{array}$ \\
\hline Pt/TiN NP & 161772678.3 & 509282547.0 & 658307300.0 & 19.7 \\
\hline Pt/TiN NT & 158151733.6 & 514022969.1 & 664434850.4 & 19.2 \\
\hline
\end{tabular}



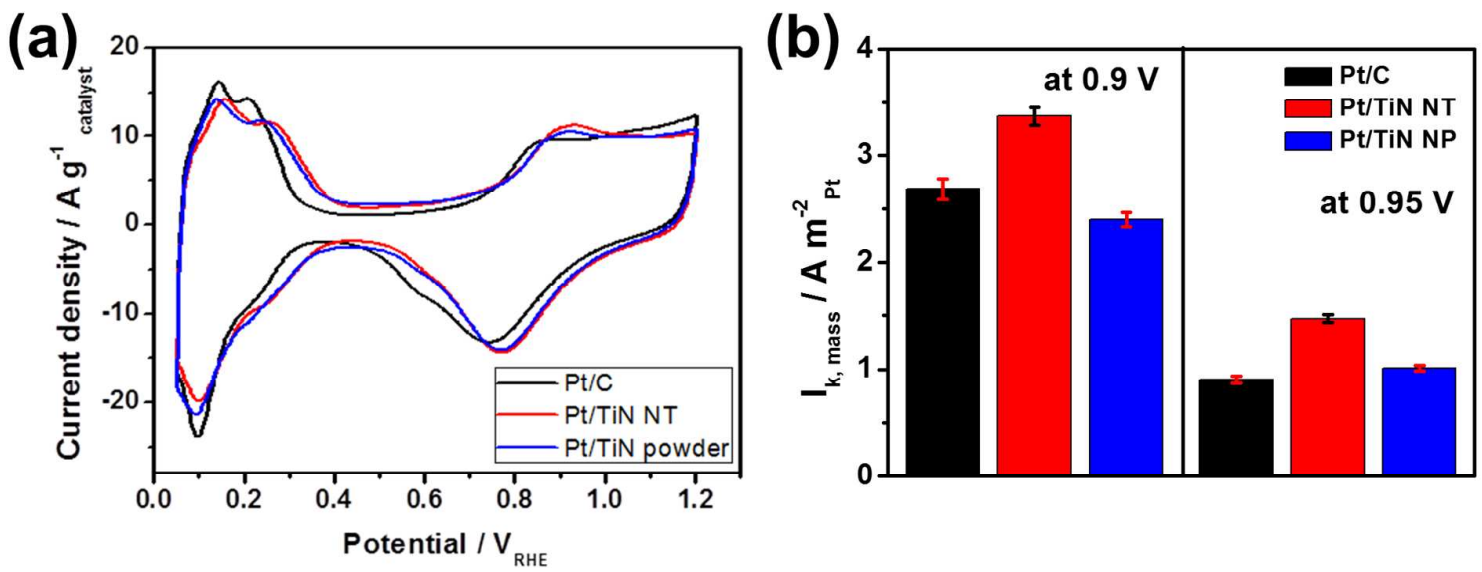

Figure S5. (a) The cyclic voltammetry of Pt catalysts measured with $20 \mathrm{mV} / \mathrm{s}$ at $293 \mathrm{~K}$ in a $0.1 \mathrm{M} \mathrm{HClO}_{4}$ solution saturated with Ar and (b) the specific activity values of catalysts at $0.95 \mathrm{~V}$ and $0.90 \mathrm{~V}$ (vs. RHE).

Table S2. ORR activities at both $0.90 \mathrm{~V}$ and $0.95 \mathrm{~V}$ (vs. RHE) and ECSA of Pt catalysts.

\begin{tabular}{|c|c|c|c|c|c|}
\hline \multirow[b]{2}{*}{ Sample } & \multirow[b]{2}{*}{$\begin{array}{c}\text { ECSA } \\
\left(\mathbf{m}_{\mathrm{Pt}}^{2} / \mathrm{g}\right)\end{array}$} & \multicolumn{2}{|c|}{$0.90 \mathrm{~V}$ (vs. RHE) } & \multicolumn{2}{|c|}{0.95 V (vs. RHE) } \\
\hline & & $\begin{array}{c}\text { Mass Activity } \\
\left.\text { (A / } \text { g }_{\mathbf{P t}}\right)\end{array}$ & $\begin{array}{l}\text { Specific Activity } \\
\left(\mathrm{A} / \mathbf{m}_{\mathrm{Pt}}^{2}\right)\end{array}$ & $\begin{array}{l}\text { Mass Activity } \\
\left(\mathbf{A} / \mathbf{g}_{\mathbf{P t}}\right)\end{array}$ & $\begin{array}{l}\text { Specific Activity } \\
\left(\mathrm{A} / \mathrm{m}_{\mathrm{Pt}}^{2}\right)\end{array}$ \\
\hline Pt/C $20 w t \%$ & 62.70 & $168.34( \pm 5.97)$ & $2.68( \pm 0.10)$ & $56.51( \pm 2.01)$ & $0.90( \pm 0.03)$ \\
\hline Pt/TiN NT & 61.29 & $206.67( \pm 5.16)$ & $3.37( \pm 0.08)$ & $90.18( \pm 2.25)$ & $1.47( \pm 0.04)$ \\
\hline Pt/TiN NP & 55.91 & $134.01( \pm 3.61)$ & $2.40( \pm 0.06)$ & $56.59( \pm 1.52)$ & $1.01( \pm 0.03)$ \\
\hline
\end{tabular}



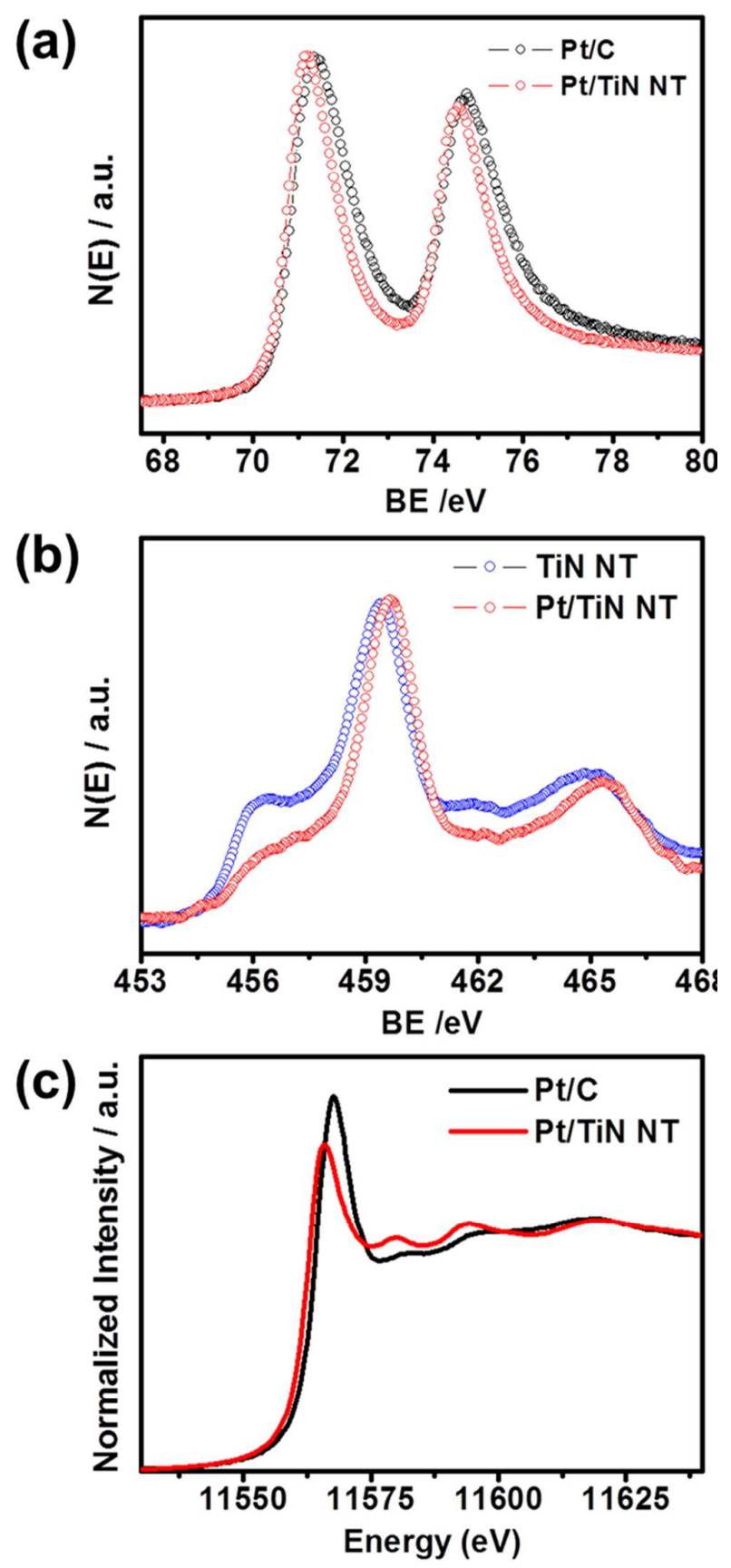

Figure S6. (a) XPS analysis (hv=630 eV, PAL 8A1 HR-PES) of Pt and (b) Ti element. (c) XANES analysis (PAL 8C) of Pt. 

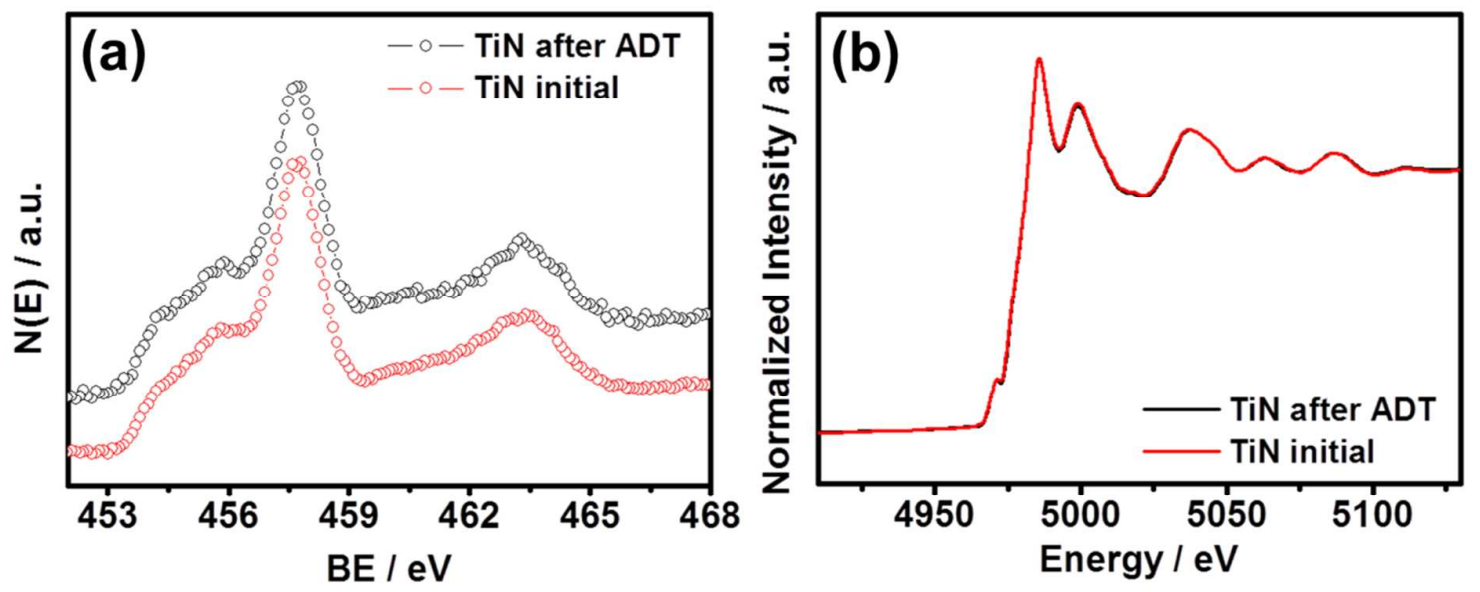

Figure S7. (a) XPS analysis (hv=630 eV, PAL 8A1 HR-PES) of Ti and (b) XANES analysis (PAL 8C) of Ti between TiN initial and after ADT samples.

(a)

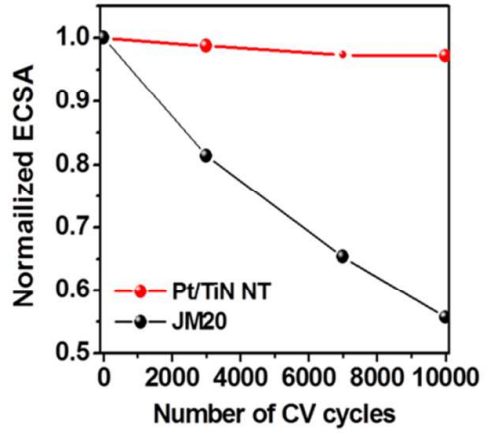

(f)

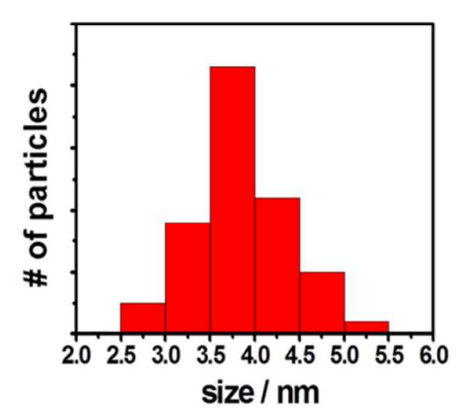

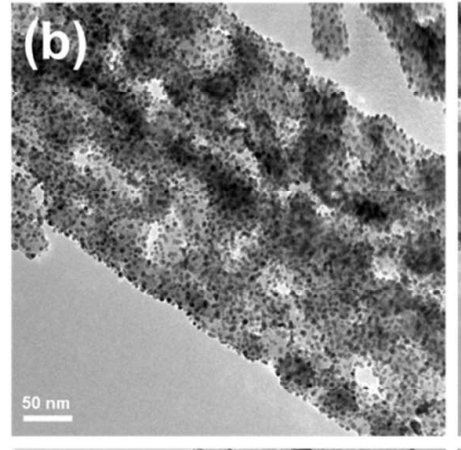
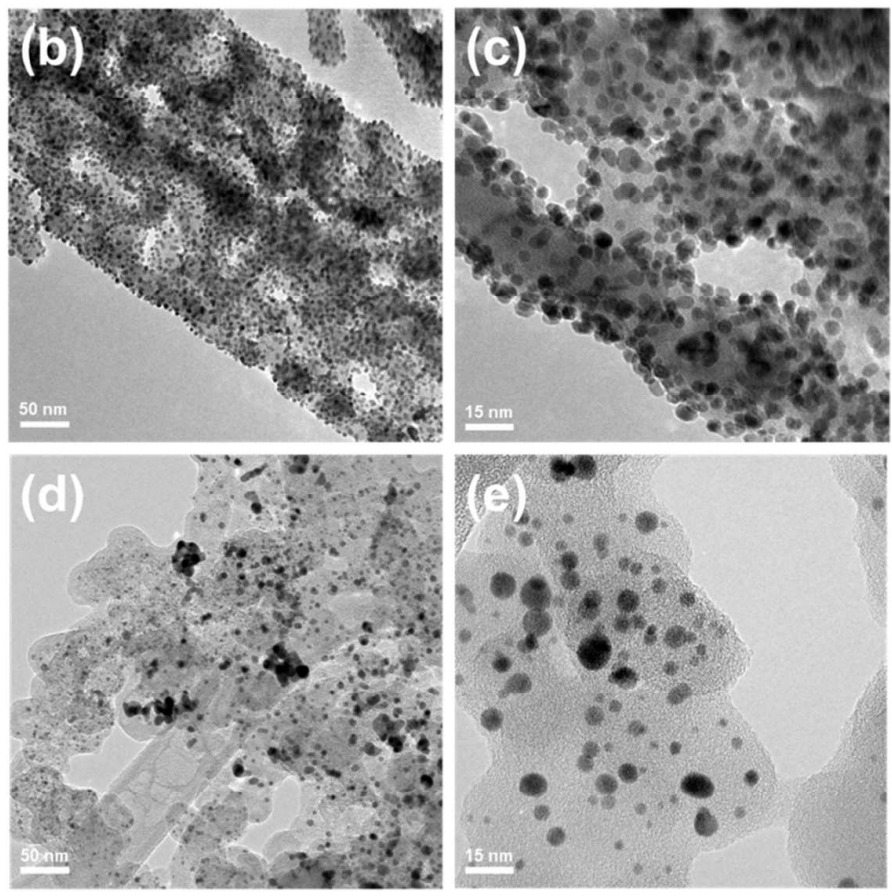

Figure S8. (a) Comparison of ESCA loss for Pt/TiN NTs and Pt/C. (b) and (c) HR-TEM images of Pt/TiN NT catalyst after ADT durability test and (f) the corresponding Pt size distribution histogram. (d), (e) Commercial $\mathrm{Pt} / \mathrm{C}$ catalyst after ADT durability test. 